\title{
Incursões sobre a estruturação da disciplina de Libras nos cursos de formação de professores
}

\author{
Implications on structuring Brazilian sign language \\ discipline in teacher training courses
}

Incursiones acerca de la estructuración de la disciplina de Libras en los cursos de formación de profesores

Karina Ávila Pereira iD

MAYARA BATAGLIN RAUGUST (iD

\section{Resumo}

O artigo busca problematizar as práticas discursivas, dentre elas as legislações que regem a disciplina de Língua Brasileira de Sinais (Libras) e as demandas da comunidade surda por transformações na estruturação dessa disciplina, as quais se estabelecem como verdades, constituindo e legitimando o ensino de Libras como segunda língua no ensino superior. Dessa forma, visa oportunizar reflexões sobre a estruturação da disciplina de Libras nas Instituições de Ensino Superior do Rio Grande do Sul. O aporte teórico conta com as principais pesquisas acadêmicas atuais da área do ensino de Libras como segunda língua, como Santos e Klein (2015), Nascimento e Sofiato (2016) e Mélo (2019). A pesquisa tem caráter qualitativo, por meio de levantamento de dados retirados das ementas e planos de ensino da disciplina de Libras de tais instituições. Foi realizada busca detalhada, catalogação e análise dos documentos mencionados, objetivando encontrar neles

\footnotetext{
a Universidade Federal de Pelotas (UFPel), Pelotas, RS, Brasil. Doutora em Educação, e-mail: karina.pereira53@gmail.com

b Universidade Federal de Pelotas (UFPel), Pelotas, RS, Brasil. Mestre em Educação, e-mail: maybataglin@hotmail.com
} 
algumas recorrências em sua estruturação. Este texto problematiza três delas: a pouca carga horária destinada à disciplina e o excesso de conteúdo a ser ensinado; a priorização de conteúdos considerados práticos em detrimento da teorização da disciplina e a generalização de conteúdos nos diferentes cursos de licenciatura. A conclusão é de que ainda são urgentes discussões com alcances mais amplos, englobando professores de Libras, coordenadores de cursos e gestão acadêmica, a fim de pensar conjuntamente a reestruturação da disciplina de Libras, dando ênfase mais às habilidades de expressão e compreensão dos dizeres da língua, mas também, formando um profissional consciente das singularidades linguísticas de seus futuros alunos.

Palavras-chave: Libras. Currículo. Formação de professores.

\begin{abstract}
This article aims to problematize the discursive practices among them, the laws that govern the discipline of Brazilian Sign Language (Libras) and the demands of the deaf community for changes in the structuring of this discipline, which constitute themselves as truths, constituting and legitimizing the teaching of Libras as a second language in higher education. It is interested in providing opportunities for reflections on the structuring of the Libras discipline in Higher Education Institutions in Rio Grande do Sul. The theoretical contribution relies on the main current academic research in the area of teaching Libras as a second language, such as Santos and Klein (2015), Nascimento and Sofiato (2016) and Mélo (2019). The research has a qualitative character, through the collection of data taken from the menus and teaching plans of the Libras discipline from these institutions. It was made a detailed search cataloging, categorization and analysis of the mentioned documents, aiming to find some recurrences about the structuring of Libras discipline. This text problematizes three aspects of them: the little workload destined to the discipline and the excess of content to be taught in this discipline; the prioritization of contents considered practical over the theorization of the discipline and; the generalization of content in the different undergraduate courses. It is possible to conclude that a reordering of the discipline is still urgent as a result of discussions with broader scope, including Libras teachers, course coordinators and academic management. At the end of this article it is possible to conclude that there is a need for a restructuring of Libras discipline, so that it focuses on the skills of expression and comprehension of language, but also that it produces a professional aware of the linguistic singularities of its future students.
\end{abstract}

Keywords: Libras. Curriculum. Teacher training.

\title{
Resumen
}

El artículo busca problematizar las prácticas discursivas, entre ellas, las leyes que rigen la disciplina del lenguaje de señas brasileño (Libras) y las demandas de la comunidad sorda de transformaciones em la estructuración de esta disciplina, que se constituyen 
como verdades, que constituyen y legitiman la enseñanza de Libras como segunda lengua en la educación superior. De esa forma tiene como objetivo proporcionar reflexiones sobre la estructuración de la disciplina de Libras en las instituciones de educación superior em Rio Grande do Sul. La contribución teórica se basa en las principales investigaciones académicas actuales en el área de la enseñanza de Libras como segunda lengua, como Santos y Klein (2015), Nascimento y Sofiato (2016) y Mélo (2019). La investigación tiene un carácter cualitativo, a través de la recopilación de datos tomados de los menús y los planes de enseñanza de la disciplina Libras de tales instituciones. Se realizó una búsqueda detallada, catalogación, categorización y análisis de los documentos mencionados, objetivando encontrar en ellos algunas recurrencias en la estructuración de la disciplina de Libras. Este texto problematiza tres de ellas: la baja carga horaria destinada a la disciplina y el exceso de contenido a ser enseñado; la priorización de contenidos considerados prácticos en detrimento de la teorización de la disciplina y la generalización de contenidos en los distintos cursos académicos. Se concluye que aún se hace urgente una reordenación de la disciplina por medio de discusiones con alcances más amplios, involucrando maestros de Libras, coordinadores de cursos y gestión académica. Por fin, se percibe la necesidad de una reestructuración de la disciplina de Libras con la finalidad de que enfoque en las habilidades de expresión y comprensión de los modos de hablar la lengua, pero también, que forme un profesional consciente de las singularidades lingüísticas de sus futuros alumnos.

Palabras Clave: Libras. Currículo. Formación de profesores.

\section{Introdução}

A pesquisa acadêmica opera constantemente com várias problematizações, buscando sempre respostas que, momentaneamente, nos satisfaçam. Enquanto objeto de constante exercício de pensamento, tais problematizações compreendem a ideia de que nada está de antemão dado e que qualquer resposta é fruto de reflexões contínuas. Em uma perspectiva filosófica, Foucault propõe em $\mathrm{O}$ cuidado com a Verdade que "problematização é o conjunto das práticas discursivas ou não discursivas que faz alguma coisa entrar no jogo do verdadeiro ou falso e o constitui como objeto para pensamento" (FOUCAULT, 2006, p. 242).

Partindo desse pressuposto, a pesquisa aqui referenciada busca apresentar interpretações referentes à disciplina de Libras como segunda língua na formação de professores. O estudo inicia a partir da análise dos planos de ensino e de ementas de tal disciplina, as quais fazem parte da matriz curricular dos cursos de licenciatura das principais Instituições de Ensino Superior do Rio Grande do Sul. O objetivo da 
pesquisa não é encontrar uma resposta pronta sobre o ensino de Libras na formação de futuros professores, mas desenvolver continuamente um exercício de pensamento, possibilitando a criação de novas e/ou outras formas possíveis, bem como a troca de saberes entre os diversos profissionais dessa área.

A pesquisa foi delineando-se a partir de alguns questionamentos iniciais feitos pelas autoras, a fim de tencioná-los e colocá-los em funcionamento na pesquisa. Destacamos três perguntas centrais para a configuração da pesquisa: quais conteúdos têm sido ensinados nas disciplinas de Libras das instituições de ensino superior do Rio Grande do Sul? Qual o objetivo da disciplina para os futuros profissionais da área da educação? A carga horária é suficiente para a quantidade de conteúdos expressos nos planos de ensino? Essas questões foram fundamentais na percepção de três recorrências encontradas na ementas e planos de ensino, as quais se configuram como categorias de análise para esta pesquisa, quais sejam: 1) a carga horária da disciplina versus o montante de conteúdo, 2) conteúdos teóricos e práticos a serem ensinados e 3) a generalização da disciplina de Libras. Tais análises são fundamentais, pois enquanto professoras de Libras há um questionamento constante em nosso cotidiano sobre os modos de ensinar, principalmente no tocante aos conteúdos, ao objetivo e ao tempo que temos.

Quanto ao referencial teórico, buscamos subsídios do que tem sido atualmente produzido no tocante a pesquisas acadêmicas sobre o ensino de Libras nos cursos de licenciatura. Este tem sido assunto recorrente em pesquisas acadêmicas, desde a publicação do Decreto 5.626, de 22 de dezembro de 2005, o qual institui o ensino de Libras nos cursos de formação de professores e no curso de fonoaudiologia. Realizamos, portanto, um levantamento minucioso de pesquisas que tenham como temática a problemática da disciplina de Libras como segunda língua nos cursos de licenciatura. A busca incluiu os principais bancos de dados do país, dentre eles o Catálogo de Teses e Dissertações da Capes ${ }^{1}$. Recorremos também à plataforma Scielo, ao Google Acadêmico e ao banco de produções da Associação Nacional de Pós-Graduação e Pesquisa em Educação (ANPED), por serem sites e

\footnotetext{
${ }^{1} \mathrm{O}$ banco de Teses e dissertações da Capes foi escolhido por compreendermos que se trata de um banco de dados que nos permite ter acesso às pesquisas mais recentes e produtivas para a composição das discussões e resultados aqui trazidos.
} 
plataformas que apresentam produções derivadas de pesquisas na área da educação reconhecidas nacionalmente. Compreendemos, portanto, que os questionamentos frente a tais materiais nos forneceram subsídios para as análises empreendidas nesta pesquisa, a qual busca problematizar como a disciplina de Libras tem sido estruturada e ofertada nas IES do Rio Grande do Sul.

\section{Delineamentos conceituais para a contextualização da pesquisa}

Estamos a todo o momento sendo constituídos pelos mais diversos discursos, dentre eles o discurso cultural, o linguístico, o político, o legal, etc., os quais operam nos diversos contextos sociais. O discurso é entendido nesta pesquisa através do conceito trazido pelos Estudos Culturais, o qual apresenta o mesmo como um conjunto de enunciados constituídos por meio da linguagem. Como afirma Fischer (2007, p.55), os discursos têm uma carga histórica, pois além de constituírem-se em determinado espaço e tempo, eles possuem uma "positividade concreta, investem-se em práticas, em instituições, em um número infindável de técnicas e procedimentos que, em última análise, agem nos grupos sociais, nos indivíduos, sobretudo nos corpos”.

Os discursos, como produção de saberes e de conhecimentos, são compostos mediante a linguagem, produtora de significados sobre todas as instâncias sociais. Dessa forma, a realidade é constituída e as coisas são legitimadas, ou seja, pelo viés dos Estudos Culturais ${ }^{2}$, a linguagem por meio das práticas sociais, por meio dos discursos, produz a realidade enquanto a nomeia.

O próprio termo "discurso" refere-se a uma série de afirmações, em qualquer domínio, que fornece uma linguagem para se poder falar sobre um assunto e uma forma de produzir um tipo particular de conhecimento. $O$ termo refere-se tanto à produção de conhecimento através da linguagem e da representação, quanto ao modo como o conhecimento é institucionalizado, modelando práticas sociais e pondo novas práticas em funcionamento (HALL, 1997, p. 10).

\footnotetext{
${ }^{2}$ Os Estudos Culturais podem ser entendidos como um campo não homogêneo que analisa as produções culturais de determinadas culturas, assim como suas práticas (PINHEIRO, 2012).
} 
Isso quer dizer que em cada discurso há a constituição de um objeto enquanto é nomeado. O objeto não está lá esperando para ser desvelado, sendo produzido enquanto o discurso também é produzido. Trazendo esses conceitos para a pesquisa em questão, o discurso produzido pela comunidade surda — por meio de suas reivindicações —, os discursos produzidos pelas Leis relacionadas ao ensino de Libras e, também, os discursos produzidos pelas pesquisas acadêmicas sobre os modos de ensinar Libras como segunda língua para ouvintes, vão constituindo-se como verdades na configuração das ementas e planos de ensino da disciplina de Libras nas IES do Rio Grande do Sul.

Podemos perceber que as práticas de ensino da Libras, os planos de ensino e as ementas são produtos de uma prática discursiva que constitui essa disciplina enquanto a nomeia. Dentre tais práticas discursivas, destacamos aquelas que, neste momento, movimentam nossas discussões. A primeira diz respeito às legislações que regem a obrigatoriedade da disciplina de Libras no ensino superior. O decreto 5.626 de 22 de dezembro de 2005, apesar de regulamentar a Lei 10.436, de 24 de abril de 2002, que oficializa a Libras como língua e dar algumas providências a seu respeito, dentre elas a obrigatoriedade do ensino da Libras para os cursos de formação de professores e Fonoaudiologia, não oferece subsídios de um panorama para este ensino. No rol das providências que o decreto oferece, encontramos no capítulo II do decreto 5.626 de 22 de dezembro de 2005 artigo que trata especificamente da inclusão da Libras como disciplina curricular, ou seja, da obrigatoriedade da disciplina de Libras nos cursos de formação de professores. Destacamos, a seguir, o artigo que trata da questão:

Art. $3^{\circ}$. A Libras deve ser inserida como disciplina curricular obrigatória nos cursos de formação de professores para o exercício do magistério, em nível médio e superior, e nos cursos de Fonoaudiologia, de instituições de ensino, públicas e privadas, do sistema federal de ensino e dos sistemas de ensino dos Estados, do Distrito Federal e dos Municípios.

$\$ 1^{\circ}$ Todos os cursos de licenciatura, nas diferentes áreas do conhecimento, curso normal de nível médio, e o curso normal superior, o curso de Pedagogia e o curso de Educação Especial são considerados cursos de formação de professores e profissionais da educação para o exercício do magistério.

Apesar da conquista da obrigatoriedade da disciplina de Libras em todos os cursos de formação de professores, possibilitando o conhecimento e a difusão da 
língua, o decreto não traz nenhum delineamento quanto à estruturação da disciplina, dando autonomia para cada instituição no tocante à elaboração da mesma. Conforme Nascimento e Sofiato (2016, p. 751), ainda que sejam levadas em conta as determinações previstas no Decreto n. 5.626/05 (BRASIL, 2005), “as diretrizes curriculares de cada curso é que regem a regulamentação da carga horária, dos conteúdos e ementas, em razão do princípio de autonomia universitária de que gozam as IES”. Igualmente, a Lei de Diretrizes e Bases da Educação Nacional (LDB) de 1996, ao elaborar as diretrizes curriculares das IES, integra em seus princípios a "ampla liberdade na composição da carga horária a ser cumprida para a integralização dos currículos” (BRASIL, 1996). Em relação à estruturação dos currículos, a Lei objetiva maior liberdade das IES “a partir da explicitação das competências e das habilidades que se deseja desenvolver, através de um modelo pedagógico capaz de adaptar-se à dinâmica das demandas da sociedade" (BRASIL, 1996).

Apesar da flexibilização dada pela LDB de 1996, no que tange à carga horária da disciplina e à estruturação dos currículos, somente em 2015 — dez anos após a regulamentação do Decreto n. 5.626/2005 — é que as Diretrizes Curriculares Nacionais para a Formação Inicial e Continuada dos Profissionais do Magistério da Educação Básica (BRASIL, 2015) passaram a referenciar a Libras como componente importante para o currículo da formação inicial e continuada do magistério da Educação Básica (MÉLO, 2019). Tal visibilidade dada tardiamente à disciplina de Libras demonstra que ainda é necessário pensarmos e discutirmos sobre ela no tocante ao seu ensino como segunda língua para ouvintes, uma vez que a estruturação dessa matriz curricular tem sido foco de diversos debates, seminários e pesquisas acadêmicas no país ${ }^{3}$. Isso porque está sendo produzida uma matriz curricular de Libras diversificada sem um parâmetro sobre quais conteúdos devem ser ensinados. Não há, portanto, um consenso entre os professores, entre as unidades acadêmicas e entre as instituições de ensino sobre quais conteúdos são

\footnotetext{
${ }^{3}$ Dentre eles o $4^{\circ}$ Seminário Franco-Brasileiro de Estudos Surdos, o $3^{\circ}$ Seminário de Educação de Surdos e Libras, o Fórum de Discussão sobre a Disciplina de Libras na Formação de Professores e o $1^{\circ}$ Encontro Nacional de Professores de Tradução e Interpretação de Libras e Língua Portuguesa das Universidades Federais. VITALINO; DALL'ACQUA; BROCHADO, 2013; SANTOS; KLEIN, 2015; NASCIMENTO; SOFIATO, 2016; MÉLO, 2019; IACHINSKI, 2019.
} 
fundamentais para a disciplina de Libras e quais podem ser readaptados ou substituídos, levando-se em consideração as especificidades de cada turma, como localidade, tempo e área do conhecimento. Além disso, tem-se estruturado a disciplina com base em matrizes curriculares não atualizadas, dificultando o processo de debate e articulação conjunta entre profissionais da área de Libras, comunidade acadêmica, comunidade surda, coordenadores e diretores de cursos. Reafirmamos com essa sistematização da matriz curricular da disciplina de Libras, busca-se a formação de um futuro professor criativo, inovador, consciente e apto na comunicação em Libras, preparado para vivenciar a realidade da educação de surdos.

A segunda prática discursiva que trazemos para esta discussão diz respeito àquelas enunciadas pela comunidade surda. Destacamos alguns apontamentos produzidos no documento intitulado "Propostas para a elaboração de uma política nacional bilíngue para surdos", elaborado pela FENEIS - Federação Nacional de Educação e Integração dos Surdos —, a partir do movimento surdo em favor da educação e cultura surda, trazendo alguns apontamentos sobre a estruturação de diretrizes para o ensino de Libras. Destacamos a "formação de um grupo de trabalho de professores surdos já atuante nas escolas e universidades públicas”, a fim de construir propostas que auxiliem tais diretrizes curriculares e que tais propostas sejam apresentadas à Secretaria de Ensino Superior e à Secretaria de Educação Básica do MEC. (CAMPELLO; REZENDE, 2012, p. 15).

Vários são os elementos que demonstram que essa disciplina tem sido ensinada de diferentes formas, não havendo padronização em sua estrutura, organização e seleção de conteúdos. Além do documento trazido acima, conversas com profissionais da área, surdos e ouvintes participantes ativos da comunidade surda, análise de pesquisas sobre a estruturação da disciplina de Libras em diversas universidades do Rio Grande do Sul e nossa própria prática em sala de aula enquanto professoras da disciplina de Libras corroboram essa percepção. Diversos professores de Libras têm relatado que numa mesma instituição a disciplina de Libras tem sido ofertada e ministrada de formas díspares pelos diversos professores, não havendo um plano de ensino padronizado a seguir. Isso permite ao professor regente de cada turma certa liberdade na escolha de conteúdos. Percebemos com isso diferentes níveis de aquisição da língua nas diversas turmas que cursam a 
disciplina, criando alguns problemas visíveis, dentre eles: diferentes níveis de aquisição linguística dos alunos que concluem a disciplina de Libras I e cursam a Disciplina de Libras II e ensino vasto de vocabulário, deixando em segundo plano as demais competências imprescindíveis na aquisição de língua, como a compreensão (escuta) visual, a fala através de estruturação de frases e conversação, interação entre conteúdo prático e o conteúdo teórico, relacionando-os ao cotidiano dos alunos cursantes da disciplina.

As incursões trazidas acima permitem certo ato questionador em relação ao que se espera da disciplina de Libras na formação de futuros professores e, de fato, como ela vem ocorrendo nos últimos anos. A partir das pesquisas acadêmicas encontradas, dos documentos legais e das demandas da comunidade surda — os quais nos servem de aporte teórico para a pesquisa — e da análise dos planos de ensino e ementas da disciplina de Libras das principais IES do Rio Grande do Sul, buscamos discutir as recorrências encontradas na estruturação dessa disciplina, bem como apresentar algumas conclusões e possíveis soluções, mesmo que incipientes e provisórias, para o cenário atual.

\section{Metodologia da pesquisa}

Esta pesquisa caracteriza-se por possibilidades de debates, não havendo, portanto, durante todo o processo de estudo a pretensão de uma verdade absoluta. Dessa forma, as balizas metodológicas, nesse momento, dão-se sob o enfoque qualitativo, por meio do levantamento de dados retirados das análises dos planos de ensino e ementas das disciplinas de Libras no ensino superior. A partir disso e sem uma preocupação com uma única e pré-definida metodologia, passamos a explicitar os caminhos metodológicos percorridos para que chegássemos às três problemáticas — ou categorias de análise — da pesquisa, bem como às possíveis conclusões.

Primeiramente, o intento de pesquisar sobre como a disciplina de Libras tem sido ministrada nas diferentes instituições de Ensino Superior do Rio Grande do Sul surgiu em 2015, quando ao ingressarmos em uma universidade pública como professoras de Libras, juntamente com colegas que vinham de outras instituições, deparamo-nos com ementas e planos de ensino diversificados. Em uma das primeiras reuniões com os demais colegas, observamos que as ementas e planos de ensino que 
cada professor havia elaborado eram díspares uns dos outros e que a estruturação da disciplina de Libras na instituição estava desatualizada. Em segundo lugar, esta pesquisa compreende uma ramificação de pesquisas maiores desenvolvidas pela área de Libras da instituição em que lecionamos, as quais englobam a educação de surdos e a formação inicial e continuada de professores de surdos 4 .

Como primeiro evento da pesquisa, fizemos uma busca detalhada através do site do Instituto Nacional de Estudos e Pesquisas Educacionais (Inep), órgão ligado ao Ministério da Educação, das principais instituições de ensino superior públicas e privadas do estado do Rio Grande do Sul. Para este estudo, levamos em consideração as instituições mais bem colocadas no ranking dos indicadores de qualidade de cursos superiores, com notas entre três e cinco no Índice Geral de Cursos (IGC). Outro fator escolhido foi a consolidação enquanto espaço acadêmico - espaço de ensino, pesquisa e extensão e social das instituições renomadas no que se refere à formação de professores.

Das 110 instituições listadas pelo Inep, 15 foram selecionadas de acordo com os pontos descritos acima. A partir desta escolha, buscamos através de contato com as coordenações de cursos, bem como por pesquisa na internet, os planos de ensino e ementas das disciplinas de Libras de cada instituição. Procuramos também pelos Planos Pedagógicos dos Cursos (PPC) e grade semestral de disciplinas para futuras análises. Obtivemos acesso às ementas das disciplinas de Libras de todas as instituições, mas apenas quatro planos de ensino. Tais documentos coletados e analisados referem-se aos anos de 2016 a 2019. Para preservação das instituições participantes da pesquisa, optamos por descrevê-las como 'Universidade 1', 'Universidade 2' e, assim, consecutivamente.

Com as ementas e planos de ensino em mãos, buscamos observar as recorrências em tais documentos a partir das questões balizadoras da pesquisa, quais sejam: quais conteúdos têm sido ensinados nas disciplinas de Libras das instituições de ensino superior do Rio Grande do Sul? Qual o objetivo da disciplina para os

\footnotetext{
${ }^{4}$ Dentre elas o Spread the Sign - Internacionalização da Libras -, projeto de pesquisa Circulação e Consumo da Cultura Surda na Formação de Professores e na Educação Básica, e o projeto de pesquisa A Produção de Sinais Emergenciais nos Espaços de Ensino/Aprendizagem das Instituições de Ensino Superior do Rio Grande do Sul.
} 
futuros profissionais da área da educação? A carga horária é suficiente para a quantidade de conteúdos expressos nos planos de ensino? Buscando responder a essas perguntas, fizemos a catalogação das IES via planilha, dividindo-as em sete categorias: Nome da IES; Curso; Carga horária total; Carga horária teórica; Carga horária prática; conteúdo programático e modalidade.

Durante o período de separação e catalogação de tais categorias, três recorrências saltaram aos olhos quanto à estruturação das disciplinas: 1) a carga horária da disciplina versus o montante de conteúdo. Ou seja, a excessiva quantidade de conteúdos práticos, principalmente de vocabulário, sem sua inserção em contextos dialógicos de produção e compreensão da língua. 2) conteúdos teóricos e práticos a serem ensinados. Isso diz respeito à divisão e separação entre conteúdos teóricos e práticos da disciplina, privilegiando-se uns em detrimento de outros. E 3) a generalização da disciplina de Libras, no que tange à estruturação da disciplina de forma global a todos os cursos de licenciatura das instituições, sem conteúdos específicos de acordo com área de atuação. Tais recorrências apresentamse como categorias de análise e buscamos, a seguir, repensá-las e contextualizá-las proporcionando aos discentes "o uso habitual da língua, enunciada e compreendida também por eles, nos mais diversos contextos de sua realização concreta, como um sistema vivo e dialógico" (ALBRES, 2016, p.153).

\section{Análise dos dados e problematizações}

A partir do acesso às ementas e aos planos de ensino de cada uma dessas 15 instituições e posterior catalogação das informações de cada uma delas, partimos para a análise das recorrências que a maioria dos planos e ementas — senão todas - possuía. Apesar da pesquisa fornecer diversos dados e recorrências, neste texto não conseguiremos problematizar todas elas e, por este motivo, traremos três categorias de análise, as quais consideramos centrais sobre a disciplina de Libras: 1) a carga horária da disciplina versus o montante de conteúdo; 2) conteúdos teóricos e práticos a serem ensinados e 3) generalização da disciplina de Libras. Buscamos com as discussões tecidas elaborar algumas proposições para a transformação nas formas de pensar e elaborar o ensino de Libras para os cursos de formação de professores. 
Além da análise dos dados, conversas informais com professores de Libras de diversas instituições foram fundamentais para os empreendimentos feitos a seguir.

\section{Carga horária da disciplina versus o montante de conteúdo}

Ao serem catalogados os dados da pesquisa, o que mais se mostrou evidente foi a relação entre a carga horária e o conteúdo programático. A disciplina de Libras, apesar de ser obrigatória por lei, não tem um padrão definido quanto a sua escala e estrutura. Das 15 instituições analisadas, 14 oferecem uma carga horária de 30 a 60 horas/aula para a disciplina e apenas 1 oferece 90 horas/aula. Além disso, 65\% das ementas analisadas dividem a mesma quantidade de horas/aula para a parte teórica e prática ${ }^{5}$ da disciplina, mas ao nos depararmos com seu conteúdo programático, percebemos uma excessiva lista de conteúdos práticos, principalmente de vocabulário, conforme quadro abaixo:

Quadro 1 - Quadro da carga horária e conteúdo programático de três IES

\begin{tabular}{|l|l|l|l|}
\hline & Universidade 1 & Universidade 6 & Universidade 9 \\
\hline $\begin{array}{l}\text { Carga Horária } \\
\text { total }\end{array}$ & 30 horas & 60 horas & 60 horas \\
\hline $\begin{array}{l}\text { Carga Horária } \\
\text { Teórica }\end{array}$ & 30 horas & 30 horas & 30 horas \\
\hline $\begin{array}{l}\text { Carga Horária } \\
\text { Prática }\end{array}$ & 0 horas & 30 horas & 30 horas \\
\hline
\end{tabular}

(continua)

\footnotetext{
${ }^{5}$ Compreendemos que teoria e prática são processos indissociáveis no tocante ao ensino. Porém, destacamos que quando nos referimos a conteúdos teóricos da disciplina de Libras, estamos nos reportando a questões que perpassam a língua, como cultura e identidade surda, educação de surdos, discussões de esfera política e legal, etc. No que tange à parte prática da disciplina, nos referimos ao exercício da língua em si, no que diz respeito às suas formulações fonológicas, morfológicas, semânticas, sintáticas e pragmáticas.
} 
Quadro 1 - Quadro da carga horária e conteúdo programático de três IES

(conclusão)

\begin{tabular}{|c|c|c|c|}
\hline & Universidade 1 & Universidade 6 & Universidade 9 \\
\hline $\begin{array}{l}\text { Conteúdos } \\
\text { teóricos }\end{array}$ & $\begin{array}{l}\text { - Visão panorâmica } \\
\text { da Libras com ênfase } \\
\text { para aspectos } \\
\text { culturais, } \\
\text { educacionais e } \\
\text { linguísticas; } \\
\text { - História das } \\
\text { comunidades, cultura } \\
\text { e identidades surdas; } \\
\text { - Políticas } \\
\text { educacionais para } \\
\text { surdos; } \\
\text { - Estudos linguísticos } \\
\text { e gramática da } \\
\text { Libras; }\end{array}$ & $\begin{array}{l}\text { - História, Educação, } \\
\text { Língua e Cultura surda; } \\
\text { - Variações linguísticas; } \\
\text { - Fonologia da Libras; }\end{array}$ & $\begin{array}{l}\text { - Introdução aos estudos } \\
\text { surdos: língua, educação, } \\
\text { cultura surda; } \\
\text { - Tradução/Interpretação } \\
\text { - Linguística da Libras } \\
\text { (fonologia, morfologia, } \\
\text { sintaxe, semântica e } \\
\text { pragmática); }\end{array}$ \\
\hline $\begin{array}{l}\text { Conteúdos } \\
\text { práticos }\end{array}$ & $\begin{array}{l}\text { - Alfabeto; } \\
\text { - Números; } \\
\text { - Tempo; } \\
\text { - Espaço/ Localização; } \\
\text { - Família; } \\
\text { - Cores; } \\
\text { - Expressões faciais e } \\
\text { corporais; } \\
\text { - Pronomes; } \\
\text { - Classificadores; } \\
\text { - Atividades diárias; }\end{array}$ & $\begin{array}{l}\text { - Alfabeto; } \\
\text { - Números; } \\
\text { - Cumprimentos; } \\
\text { - Calendário; } \\
\text { - Pronomes; } \\
\text { - Advérbios de lugar; } \\
\text { - Verbos; } \\
\text { - Grau de parentesco; } \\
\text { - Estado Civil; } \\
\text { - Adjetivo; } \\
\text { - Antônimos; } \\
\text { - Sentimentos; } \\
\text { - Grau comparativo; } \\
\text { - Semana; } \\
\text { - Turno; } \\
\text { - Advérbios de tempo; } \\
\text { - Animal; } \\
\text { - Natureza; } \\
\text { - Localização de objetos na } \\
\text { sala de aula; }\end{array}$ & $\begin{array}{l}\text { - Alfabeto Manual; } \\
\text { - Números; } \\
\text { - Saudações; } \\
\text { - Ambiente doméstico e } \\
\text { escolar; } \\
\text { - Espaços urbanos; } \\
\text { - Calendário; } \\
\text { - Natureza; } \\
\text { - Família; } \\
\text { - Cores; } \\
\text { - Alimentação; } \\
\text { - Animais; } \\
\text { - Materiais escolares; } \\
\text { - Profissões; } \\
\text { - Pronomes; } \\
\text { - Advérbio de tempo; } \\
\text { - Classificadores; } \\
\text { - Verbos; } \\
\text { - Diálogos; }\end{array}$ \\
\hline
\end{tabular}

Fonte: Dados coletados para fins desta pesquisa.

Com relação a isso, Martins (2008, p. 202-203) nos alerta sobre os "perigos de transformarmos a disciplina de Libras num manual de ensino rápido que facilita e promove, por si, o acesso à inclusão", pois desse modo "seríamos assim traídos porque de fato não é esse o intuito". Isso nos permite dizer que, assim como a 
aprendizagem de qualquer outra língua, a Libras demanda tempo maior que um semestre para ser apreendida em sua complexidade tanto prática quanto teórica, pois como sabemos, as línguas não são constituídas isoladamente, mas pertencem a um arcabouço cultural, social, histórico, político, etc.

No tocante ao ensino prático da Libras, há uma incoerência entre carga horária e conteúdo programático. Isso porque a aprendizagem da Libras perpassa seus níveis linguísticos como a Fonética e Fonologia, Morfologia, Sintaxe, Semântica e Pragmática. Vale ressaltar também, que não são apenas as mãos que são utilizadas na produção de um sinal nas línguas de sinais. Muitos sinais utilizam as marcações não manuais, também chamadas de expressões faciais e corporais. Estas, como nos diz Gesser (2009, p. 18) podem ser comparadas aos "traços paralinguísticos das línguas orais (entonação, velocidade, ritmo, sotaque, expressões faciais, hesitações, entre outros" e dizem respeito aos movimentos da cabeça, dos olhos, do corpo, da boca, das sobrancelhas, das bochechas que compõem a estrutura da língua.

A partir da explicação inicial concedida sobre a estrutura da Libras, podemos indicar a incoerência anteriormente mencionada entre a carga horária da disciplina e os conteúdos práticos que têm sido ensinados. Isso nos permite afirmar que a maleabilidade no processo de estruturação da disciplina, assim como nos aponta Mercado (2012, p. 66), é insuficiente para formar alunos fluentes em Libras e aptos a serem professores bilíngues, pois "apesar de objetivar a preparação do professor para incluir o surdo na escola regular e desenvolver sua alfabetização, é notável que a organização dos planos não permite a efetivação desses objetivos". Tal fato é corroborado pelo fato de a disciplina de Libras ser semestral, com pouca carga horária e não haver a obrigatoriedade de continuidade da disciplina nos demais semestres — sendo apenas inserida na grade curricular como disciplina optativa o volume de conteúdos descritos nas ementas das disciplinas é relativamente grande para ser ensinado num curto espaço de tempo, principalmente pelo fato de que, em sua maioria, as disciplinas de Libras das instituições analisadas compartilham carga horária com conteúdos teóricos.

Analisando outras pesquisas feitas sobre a carga horária da disciplina de Libras nos cursos de licenciatura, como Nascimento e Sofiato (2016), Giroto, Martins e Lima (2015), Costa e Lacerda (2015), dentre outros, observamos que, em 
sua totalidade, tais pesquisas apontam como uma das fragilidades do desempenho da disciplina de Libras, sua pequena carga horária, sendo algo indicado também pelos discentes. De acordo com a pesquisa de Nascimento e Sofiato (2016, p. 365), "muitos pedagogos que tiveram a disciplina de Libras em sua graduação não se sentem capazes de ministrar aulas para alunos surdos nesta língua”. Os autores ainda concluem que, conforme suas análises, somente uma disciplina de Libras semestral "não poderá atender a esta demanda, uma vez que não oferecerá uma formação linguística, ou seja, não promoverá a competência em Libras e em didática específica para o ensino de surdos" (Idem).

A grande demanda de conteúdos práticos nas emendas e planos de ensino é decorrente, então, da flexibilidade que as instituições têm na estruturação dessa disciplina, o que concordamos em ser um ponto positivo, pois permite que tais instituições tenham autonomia, característica que está sendo cada vez mais suprimida das mesmas. Contudo, existe um fator apresentado por Albres (2016) que consiste na carência de cursos de formação de professores de qualidade e que disponham em seu currículo de disciplinas relacionadas à didática e às metodologias de ensino. De acordo com a autora, ainda há falta de "um conhecimento técnicopedagógico, pouco privilegiado na carga horária" (ALBRES, 2016, p. 184) dos cursos de formação de professores para o ensino de Libras. Isso acontece em decorrência de uma carência de cursos de formação de professores que disponham de disciplinas didáticas e metodológicas de ensino de Libras. Como afirma Albres (2016), até pouco tempo no Brasil os professores de Libras não tinham muitos recursos e discussões teórico-metodológicas sobre o ensino de segunda língua, constituindo seus modos de ensino por meio da prática cotidiana de sala de aula. Tal fato tomou forma, conforme Albres (2016, p. 26),

Graças a pelo menos três fatores: primeiro, devido à falta de espaço acadêmico para esse tipo de discussão/formação, que fosse acessível linguística e culturalmente a essa comunidade, e pelo recente reconhecimento da Libras; segundo, pela concepção inadequada de que para se ensinar uma língua basta ser proficiente ou falante nativo dela [...]; e terceiro, pela crença de que as pesquisas e metodologias de ensino de línguas orais não poderiam auxiliar a reflexão sobre o processo de ensinoaprendizagem de línguas de modalidade viso-gestual como a Libras.

Ainda hoje, apesar de o número de materiais metodológicos bem como o de pesquisas nesta área terem aumentado, o acesso a materiais didáticos que auxiliem 
na estruturação da disciplina de Libras não é facilitado. Os professores de Libras, ao enfrentarem essa dificuldade, são praticamente obrigados a recorrer a outros meios de informação, como ensinar a língua da mesma forma que foram ensinados há anos ou buscar essas informações em conversas informais com outros professores. Muitos professores de Libras são fluentes na língua, mas encontram dificuldades na forma de ensino da mesma. Lacerda, Caporali e Lodi (2004) compreendem a importância de investimentos na formação desses professores, a partir de conhecimentos teórico-práticos que subsidiem um pensamento crítico a respeito das formas de ensinar a língua, bem como de metodologia e didáticas adequadas.

É preciso refletir que o excesso de vocabulário passado em aula, sem estratégias de ensino que levem os alunos a uma reflexão sobre a língua, sobre sua gramática e sua estruturação, bem como a formação de sentenças e diálogos, tornase uma memorização de sinais sem nenhum sentido, sem significado para a compreensão e conversação efetiva. De fato, muitos dos planos de ensino analisados, conforme a Tabela 1, voltam-se para o ensino de conteúdos práticos visando o vocabulário, sem abordar de forma mais específica a gramática da Libras. Essa prática de apenas ensinar um número excessivo de sinais sem contextualizá-los gramaticalmente e sem aplicá-los aos diálogos em Libras pode desencadear no aluno apenas a sensação da necessidade de memorização dos sinais apenas no momento da disciplina, podendo este, posteriormente, não conseguir aplicá-los em seu contexto educacional, caso tenha um aluno surdo.

Possivelmente, a argumentação de aumento de carga horária da disciplina seja uma das propostas que mais atraia os profissionais da área, demandando certo tempo para tal mudança, bem como discussões estruturais na grade curricular dos cursos de graduação. Nesse caso, é preciso uma parceria entre os docentes das disciplinas de Libras e demais coordenadores de cursos e áreas afins, possibilitando traçar um plano de ensino que contemple a relação entre a carga horária e o conteúdo programático. Da mesma forma, é necessário pensar conjuntamente em uma reestruturação dos conteúdos das disciplinas, buscando contemplar no ensino todas as habilidades e competências envolvidas na aquisição da língua, mesmo que de forma introdutória, assim como os conteúdos teóricos que englobam a Libras, como cultura, identidade, comunidade, etc. Dessa composição coletiva, poderia 
construir-se de fato "conhecimento tanto na perspectiva de teorias sobre metodologias de ensino, didática visual e de materiais específicos para o ensino de Libras" (ALBRES, 2016, p. 154).

\section{Conteúdos teóricos e práticos a serem ensinados}

Como dito anteriormente, $65 \%$ das instituições analisadas possuem a mesma carga horária para discussões teóricas e para a prática da língua. Para uma melhor visualização dos dados, segue abaixo o quadro, apresentando as 15 instituições de ensino pesquisadas, bem como a carga horária da disciplina em análise:

Quadro 2 - Instituições e carga horária da disciplina de Libras

\begin{tabular}{|c|c|c|c|}
\hline & Carga horária total & $\begin{array}{l}\text { Carga } \\
\text { teórica }\end{array}$ & Carga horária prática \\
\hline Universidade 1 & 30 horas & 30 horas & 0 horas \\
\hline Universidade 2 & 30 horas & 15 horas & 15 horas \\
\hline Universidade 3 & $\begin{array}{l}60 \text { horas } \\
30 \text { horas } \\
60 \text { horas } \\
60 \text { horas }\end{array}$ & $\begin{array}{l}45 \text { horas } \\
15 \text { horas } \\
30 \text { horas } \\
60 \text { horas }\end{array}$ & $\begin{array}{l}15 \text { horas } \\
15 \text { horas } \\
30 \text { horas } \\
0 \text { horas }\end{array}$ \\
\hline Universidade 4 & 60 horas & 30 horas & 30 horas \\
\hline Universidade 5 & 60 horas & 16 horas & 24 horas \\
\hline Universidade 6 & 60 horas & 30 horas & 30 horas \\
\hline
\end{tabular}

(continua) 
Quadro 2 - Instituições e carga horária da disciplina de Libras

\begin{tabular}{|c|c|c|c|}
\hline & Carga horária total & Carga horária teórica & Carga horária prática \\
\hline Universidade 7 & 60 horas & 60 horas & 0 horas \\
\hline Universidade 8 & $\begin{array}{l}40 \text { horas } \\
30 \text { horas }\end{array}$ & $\begin{array}{l}20 \text { horas } \\
15 \text { horas }\end{array}$ & $\begin{array}{l}20 \text { horas } \\
15 \text { horas }\end{array}$ \\
\hline Universidade 9 & 60 horas & 30 horas & 30 horas \\
\hline $\begin{array}{l}\text { Universidade } \\
10\end{array}$ & 55 horas & 25 horas & 35 horas \\
\hline $\begin{array}{l}\text { Universidade } \\
11\end{array}$ & 60 horas & 15 horas & 45 horas \\
\hline $\begin{array}{l}\text { Universidade } \\
12\end{array}$ & 30 horas & 15 horas & 15 horas \\
\hline $\begin{array}{l}\text { Universidade } \\
13\end{array}$ & $\begin{array}{l}30 \text { horas } \\
60 \text { horas }\end{array}$ & $\begin{array}{l}15 \text { horas } \\
30 \text { horas }\end{array}$ & $\begin{array}{l}15 \text { horas } \\
30 \text { horas }\end{array}$ \\
\hline $\begin{array}{l}\text { Universidade } \\
14\end{array}$ & 60 horas & 30 horas & 30 horas \\
\hline $\begin{array}{l}\text { Universidade } \\
15\end{array}$ & 60 horas & 30 horas & 30 horas \\
\hline
\end{tabular}

Fonte: Dados coletados para fins desta pesquisa.

A maioria das universidades analisadas possui uma divisão igual entre a parte prática e teórica da disciplina, no entanto, conforme a Quadro 2, notamos que algumas instituições possuem disciplinas de Libras diferentes de acordo com o curso em questão. Isto é, dependendo do curso há uma disciplina somente teórica ou teórico-prática. Apenas três das instituições observadas possuem uma carga horária apenas teórica para a disciplina de Libras.

Estes dados corroboram com o que pesquisadores de instituições de diversas partes do Brasil têm concluído sobre a disciplina de Libras: que apesar de já se 
passarem quatorze anos na publicação do Decreto sobre a obrigatoriedade desta disciplina nos cursos de formação de professores e de fonoaudiologia, ainda se fazem necessárias discussões e reformulações nos modos de estruturação desta. Isso porque, apesar do tempo decorrido desde a aprovação, é possível encontrarmos certo engessamento na estruturação de conteúdos, sobretudo porque ainda segue-se o modelo de ensino "apresentado no curso básico "Libras em Contexto” [de Tânya Amara Felipe (2007)]; maior distribuição do conteúdo para discussão sobre a língua e a surdez em detrimento ao ensino da Libras” (LEMOS; CHAVES, 2012, p. 2285).

O livro mencionado foi publicado em sua primeira edição no ano de 1997, apesar da sua mais recente edição datar de 2007. Trata-se de material de grande importância para a aprendizagem básica da Libras, possuindo 187 páginas e um DVD com exercícios práticos. Porém, como o próprio material sinaliza, ele tem melhor aproveitamento em cursos de Libras que tenham por finalidade "formar instrutores de Libras e capacitar professores para o uso desta língua em sala de aula a partir do reconhecimento linguístico dos alunos surdos" (FELIPE, 2007, p. 9). Ou seja, tal material não foi produzido para a formação de futuros professores, principalmente por ser um livro extenso que não consegue ser contemplado em sua totalidade em apenas um semestre, além de estar desatualizado. Referimo-nos a "desatualizado" no sentido de que, sendo uma língua viva, a Libras reconfigura-se e transforma-se a todo o momento, reorganiza-se discursiva, visual e espacialmente, existindo hoje sinais, gírias, parâmetros novos, bem como materiais atualizados e condensados para o ensino de Libras a ouvintes.

Já com relação à indicação de carga horária entre teoria e prática das ementas pesquisadas ela, na sua maioria, tem uma distribuição igualitária de seus conteúdos. A média da carga horária das disciplinas varia entre 30 e 60 horas aula, sendo que cerca de 15 a 30 horas são destinadas à teoria e também à prática. A partir desse dado, trazemos dois questionamentos para esta seção: será possível que uma disciplina que possui de 15 a 30 horas de aulas práticas sobre a língua consiga formar professores capazes de se comunicar em Libras? E mais, partindo do pressuposto de que o Decreto 5.626 descreve em seu artigo $14^{\circ}$, parágrafo 10 , inciso III, alínea da provisão nas escolas de "professor regente de classe com conhecimento acerca da singularidade linguística manifestada pelos alunos surdos", 
será provável uma reestruturação da disciplina de Libras que leve em consideração, sobretudo, tal conhecimento esperado deste profissional?

Com relação à pequena carga horária para a aprendizagem da Libras, concordamos com a pesquisa de Iachinski et al. (2019) que constatou, por meio da percepção dos acadêmicos de licenciatura sobre a disciplina de Libras que, após finalizarem tal disciplina, a maioria ainda não se declara pronta para ensinar alunos surdos, sentindo a necessidade de uma formação complementar em Libras, especificamente na aprendizagem da língua. Da mesma forma, a pesquisa de Martins e Ribeiro (2015) aponta para a insuficiência na carga horária da disciplina de Libras para o aprendizado prático da língua. Disso decorre o que as autoras nomeiam como um "currículo mínimo que favorece o discurso da inclusão de surdos, de modo raso e superficial, na medida em que, aparentemente, forma professores com domínio linguístico para atender as especificidades educacionais de alunos surdos" (MARTINS; RIBEIRO, 2015, p. 34).

Com relação ao segundo questionamento, consideramos como uma possível resposta a pesquisa de Vitalino, Dall'Acqua e Brochado (2013, p. 119), na qual os autores demonstram que os professores responsáveis pelas disciplinas de Libras, em sua maioria, "consideram importante que o ensino da Libras se dê atrelado ao conhecimento sobre a cultura surda, o processo de interpretação Libras-Português / Português-Libras", ou seja, tudo o que perpassa a realidade de uma língua, como comunidade, identidade, cultura. Da mesma forma, tais professores destacam a valorização no ensino de aspectos "envolvidos no processo educacional da pessoa surda, especialmente o bilinguismo e o processo de inclusão" (Idem).

Tal elucidação reforça as conclusões trazidas na pesquisa desenvolvida por Nascimento e Sofiato (2016), na qual as autoras buscam discutir sobre o desenvolvimento da disciplina de Libras nos cursos de Pedagogia de duas instituições de São Paulo. De acordo com as pesquisadoras, após análise dos planos de ensino da disciplina e questionário com os alunos, o caráter mais teórico da disciplina "visa situar a educação de surdos no universo escolar, desmistificar concepções e generalizações sobre as pessoas surdas que foram se cristalizando na cultura escolar, amparadas, muitas vezes, pelo senso comum” (2016, p. 357). Isso não quer dizer que não se tenha uma parte prática da disciplina. No entanto, a parte 
prática visa o ensino básico da Libras, pois o objetivo da disciplina, segundo as autoras, é "levar ao aluno o conhecimento da realidade da educação dos surdos no Brasil, refletindo sobre suas singularidades e a diferença linguística enquanto principal condição para o ensino destes alunos" (NASCIMENTO, SOFIATO, 2016, p. 358).

Ou seja, a disciplina busca uma reflexão em relação à educação de surdos, como a comunicação em uma língua de recepção e enunciação diferente da do ouvinte, a importância dessa língua para a aprendizagem de conteúdos pelos alunos surdos, a necessidade de se conviver em pares - e isso inclui tanto crianças quanto adultos surdos —, a formas de aprendizagem visual da Libras e do português escritos como segunda língua, dentre outras (Idem). Nesse sentido, conforme Iachinski et al. (2019, p. 6), muito mais do que ensinar uma gama de conteúdos teóricos e práticos para os futuros professores de surdos, ensinar Libras é formar um educador que reconheça os surdos, sua língua de direito, sua cultura e os modos como se dão a educação de surdos, estando, assim, melhor preparados para "interagir com ele e, inclusive, empoderá-lo no seu agir".

\section{A generalização da disciplina de Libras}

Aprender a língua de sinais não significa conhecer somente vocabulário, pois sabemos que se não houver contato constante com essa língua terminamos esquecendo o vocabulário estudado. Igualmente, o aprendizado de uma língua precisa de tempo para maturação, ou seja, não adianta o professor ensinar uma grande quantidade de conteúdos em sala de aula se não houver a compreensão de que o aluno precisa de tempo para internalizar esse aprendizado. Consoante a isso, é preciso envolver-se com as questões que permeiam essa língua, como a cultura, a comunidade, a história, a política, a legislação. Todavia, ao invés de aprendê-los de forma generalizada, não seria mais proveitoso para os acadêmicos que, provavelmente, terão apenas essa disciplina durante todo o seu curso, aprender tais conteúdos direcionados à sua formação? Esta questão torna-se mais pertinente ao olhar para o tabela a seguir: 
Tabela 1 - comparação entre as IES sobre os conteúdos gerais e específicos de cada disciplina de Libras

Número de instituições

\begin{tabular}{l|c}
\hline Total de instituições & 15 \\
$\begin{array}{l}\text { Um curso atendido com a disciplina de } \\
\text { Libras }\end{array}$ & 1 \\
$\begin{array}{l}\text { Mais de um curso atendido pela } \\
\text { disciplina de Libras }\end{array}$ & 14 \\
$\begin{array}{l}\text { Plano de ensino com conteúdos } \\
\text { específicos do curso }\end{array}$ & 0 \\
Mesmo conteúdo para todos os cursos & 15
\end{tabular}

Fonte: Dados coletados para fins desta pesquisa (PEREIRA; RAUGUST, 2019).

Ao observarmos a Tabela 1 percebemos que todas as instituições que analisamos dispõem de mais de um curso de licenciatura e todos eles apresentam nas ementas e planos de ensino os mesmos componentes curriculares. Ou seja, a disciplina de Libras tem sido ensinada de maneira geral, independentemente do curso em questão. Tal dado fortalece o que Pereira (2008) afirma em sua pesquisa: que a disciplina de Libras é ofertada, muitas vezes, desconectada do restante da matriz curricular dos cursos de licenciatura, sendo a única disciplina no currículo que contempla a educação de surdos. É por esse fato que continuamos afirmando que simplesmente aprender sinais de um dicionário de Libras não torna alguém realmente eficiente nessa língua. Pensando na seleção de conteúdos a serem ensinados, destacamos que o professor, no papel de quem conduz o aluno à construção de conhecimento, necessita em seu fazer "ter claros os seus objetivos, selecionar conteúdos pertinentes, enxergar na produção de seus alunos o que eles já sabem e construir estratégias que os levem a conquistar novos patamares de conhecimento (WEIZ, 2000, p. 53-54).

Do exposto acima pelo pesquisador Weiz, advém outra recorrência analisada nos materiais: a falta de estruturação de um plano de ensino pensado para as peculiaridades de cada curso. Ou seja, a maioria dos planos de ensino estrutura-se de forma geral, contemplando os mesmos conteúdos, tanto teóricos quanto práticos, 
para todos os cursos aos quais atende. Essa elaboração ampla dos conteúdos que dizem respeito à disciplina de Libras deixa de levar em conta que cada área de atuação do futuro profissional docente necessita de sinais próprios e de problematizações teóricas específicas. Isso porque são muitos os desafios encontrados na hora de estruturar a disciplina de Libras.

De acordo com Nascimento e Sofiato (2016), a maioria dos acadêmicos que já cursaram a disciplina de Libras enfoca a importância do ensino de terminologias adequadas para sua área de formação, além de assinalarem a vontade de inserção no contexto surdo. Conforme as autoras, os alunos pesquisados “indicaram o desejo de um contato maior com a comunidade surda, seja por meio de visitas ou estágios em escolas que contemplem esse alunado" (NASCIMENTO; SOFIATO, 2016, p. 364). A partir de tais colocações, elas concluem que este fato "demonstra o quanto essa realidade educacional é desconhecida pela maioria dos alunos", além de denotar a importância da disciplina de Libras para a formação desses profissionais e o quanto ela pode ser um mobilizador de futuros professores engajados na educação de surdos.

Ao pensar no ensino básico da Libras para os acadêmicos compreendemos, assim como as autoras acima, a importância do ensino de sinais específicos de cada área, principalmente porque posteriormente esses profissionais poderão trabalhar em uma escola de surdos ou em escolas que tenham surdos incluídos. O professor de Libras no momento de elaboração de sua disciplina precisa levar em consideração as especificidades da área de futura atuação de seus alunos. É imprescindível a conscientização de que ensinar a língua de sinais é mais do que essencialmente vocabulário, bem como mais do que apenas usar a língua entre interlocutores. Ensinar a Libras é pensar sobre ela, em como e onde ela será utilizada pelos futuros profissionais que estão aprendendo, em quais contextos esses professores a utilizarão e, a partir dessas reflexões, estruturar uma disciplina teóricoprática que possibilite problematizações teóricas sobre o contexto da língua e de seus falantes e um ensino prático de sinais que sejam usuais no cotidiano profissional desses acadêmicos.

De fato, a estruturação da disciplina de Libras deveria consistir no ensino daquilo que está atrelado ao domínio do curso de licenciatura em que se está 
ministrando a disciplina. Assim, o ensino de conteúdos direcionados a cada área de atuação poderia desencadear maior interesse dos alunos pela área da surdez. Da mesma forma, conhecer a realidade da educação de surdos não somente nas discussões em sala de aulas, mas por meio de parcerias entre a universidade e a escola de surdos, contribuiria para esse despertar de interesse em se relacionar com essa comunidade. Visitas e até estágios na escola de surdos, participação em eventos culturais da comunidade surda e o contato com pessoas surdas fornece ao acadêmico a oportunidade de aproximar-se da realidade em que futuramente poderá atuar, desde já preparando-o para tal carreira.

Tal proposta demonstra que apesar da "autonomia universitária e do fato de que as diretrizes curriculares de cada curso sobrepõem-se aos dispositivos como o Decreto n. 5.626/2005" (GIROTO; MARTINS \& LIMA, 2015, p. 753), tais instituições, juntamente com os docentes de Libras, têm a oportunidade de construir uma disciplina de Libras que esteja em consonância com a grade curricular e com as necessidades de cada curso, a fim de qualificar os futuros professores conscientizando-os sobre a escolarização dos surdos (Idem). Dessa forma, contextualizar o futuro docente sobre as discussões que se têm produzido no campo da educação de surdos — em relação à sua área em específico —, bem como os sinais utilizados para uma boa comunicação entre professor e aluno são necessidades básicas urgentes para as instituições de ensino. Ter claro, por parte do professor, que seu objetivo não é tornar seu aluno fluente na língua de sinais, mas dar condições básicas para que este profissional possa minimamente comunicar-se com seu aluno, também torna-se uma prioridade no momento de discutirmos e reestruturarmos a disciplina de Libras.

\section{Considerações finais}

Estruturar e oferecer a disciplina de Libras nos cursos de formação de professores deveria, principalmente, ter como objetivo "[...] oferecer conhecimento acerca dos surdos e da Libras para uma atuação profissional favorável e que respeite a diferença linguística do surdo" (NASCIMENTO; SILVA; NANTES, 2012, p. 12225). No entanto, como vimos no decorrer do texto, após quatorze anos da publicação do decreto que instituiu a inserção de tal disciplina nos cursos de 
formação de professores, ainda é preciso que problematizemos a seu respeito, principalmente pela forma como ela tem sido organizada e ofertada nestes cursos.

Dessa forma, algumas conclusões podem ser feitas com base nas análises realizadas. Em primeiro lugar, a necessidade urgente de uma reordenação da disciplina através de discussões com alcances mais amplos, englobando professores de Libras, coordenadores de cursos e gestão acadêmica. Tal ação poderia oferecer resultados positivos para esta disciplina, em específico, tirando-a de um status descontextualizado no interior da grade curricular dos cursos de licenciatura e interligando-a com outras disciplinas, como aquelas ligadas a metodologias de ensino, políticas educacionais, gestão escolar, chegando até mesmo, às disciplinas de estágio supervisionado em escolas de surdos ou escolas que tenham alunos surdos incluídos. Estas duas últimas opções seriam para aqueles alunos que desejarem trabalhar com esse público e queiram especializar-se e aprofundar seus conhecimentos, tanto na língua como na educação de surdos. Da mesma forma, é preciso reestruturar a disciplina de Libras, a fim de que os alunos adquiram principalmente "conhecimentos sobre letramento em Língua Portuguesa como segunda língua e "[...] estratégias de ensino e metodologias específicas para alunos surdos de forma a garantir uma educação de qualidade para os alunos em questão" (NASCIMENTO; SOFIATO, 2016, p. 366).

Os problemas acima descritos são percebidos principalmente pela falta de uma formação de professores de línguas de qualidade, que apresente, discuta e desenvolva ações voltadas para a metodologia do ensino da língua, compreendendo a importância da "mediação pedagógica, [...] da sensibilização para a condução da aprendizagem do outro (ouvinte), "estrangeiro" em língua de sinais" (ALBRES, 2016, p. 52). Pensar o outro, esse aluno ouvinte, estrangeiro, que nunca teve contato com a língua de sinais e com a comunidade surda é essencial para a construção de uma disciplina que foque nas habilidades de expressão e compreensão dos dizeres na língua. Sobretudo mais do que isso, que contribua para um profissional consciente das singularidades linguísticas de seus futuros alunos.

Em segundo lugar, ensinar Libras é ensinar o outro a pensar na/em Libras e a comunicar-se em Libras e não apenas utilizar sinais isolados, descontextualizados com a área de atuação do outro. Da mesma forma, faz parte do ensino da Libras 
levar a uma compreensão da condição linguística do surdo, da sua cultura, da sua comunidade e de todo o processo educacional, abordando questões que digam respeito à sua experiência visual, ao aprendizado da Libras como primeira língua e da língua portuguesa escrita como segunda língua, o papel do tradutor/intérprete nesse processo e, principalmente, "do seu papel como professor regente frente ao aluno surdo e ao intérprete na sala de aula" (SANTOS; KLEIN, 2015, p. 19). Para isso, partimos da ideia de que é preciso repensar em conjunto a estruturação do ensino de Libras, não apenas no que diz respeito à carga horária dessa disciplina, mas também nos conteúdos ali envolvidos, buscando-se uma coerência e interrelação entre conteúdos e ações de ensino.

Tendo-se esse pensamento, indo além de uma preparação para ensinar uma língua a fim de obter de seus alunos a fluência nela, ter contato com conteúdos que abordem as singularidades desses sujeitos e de sua aprendizagem - como o uso de didáticas e estratégias no contexto de sala de aula — tudo isso, torna mais atraente o aprendizado da Libras, preparando o futuro professor para receber e ensinar um aluno surdo. Gesser (2012) ressalta a importância do ensino de Libras e dos demais conteúdos para os alunos ouvintes:

Motivar os alunos a entenderem "o que é a surdez", "o que é a Libras", "a quem essa língua importa e por que importa", "o que ela tem a ver com as pessoas na nossa sociedade" prepara os aprendizes para a inserção e a conscientização de um repertório de conhecimentos possivelmente alheios a sua realidade, tornando-os mais bem preparados para transitar em práticas culturais que se fazem em grupos humanos diversos (p. 129).

Por fim, não podemos deixar de levar em consideração todos os avanços com relação a esta disciplina, desde que o Decreto n. 5.626/2005 foi instaurado, pois conforme Nascimento e Sofiato (2016, p. 364), a inserção dessa disciplina nos currículos é positiva, no sentido de garantir-se "ao menos, que a questão se coloque em discussão entre os futuros professores". No entanto, também não podemos ter acomodação com tais discursos, que nos concedem verdades momentâneas; precisamos nos questionar de tempos em tempos, potencializando a emergência de novos enunciados que desestabilizam àqueles que conservam as estruturas das disciplinas do ensino da Libras no ensino superior. Desse ato questionador, surgem as elucidações trazidas no presente texto, a fim de que mais do que aceitar, 
pensemos sobre elas e coloquemos em movimento outros enunciados, ou seja, outros modos, jeitos, estratégias, metodologias, estruturações, problematizações sobre a disciplina de Libras, que possam ser avaliados como satisfatórios, mas por um curto tempo e apenas por agora.

\section{Referências}

ALBRES, N. A. Ensino de Libras: aspectos históricos e sociais para a formação de professores. Curitiba: Appris, 2016.

ALMEIDA, J. J. F.; VITALINO, C. R. A Disciplina de Libras na Formação Inicial de Pedagogos: experiências dos graduandos. In: ANPED Sul - SEMINARIO DE PESQUISA EM EDUCAÇAO DA REGIAO SUL, IX ANPED Sul, 2012, Caxias do Sul. A PósGraduação e Suas Interlocuções com a Educação Básica. p.1-15.

BRASIL. (2005). Decreto $\mathrm{n}^{\circ}$. 5.626, de 22 de dezembro de 2005. Regulamenta a Lei $\mathrm{N}^{0}$ 10.436, de 24 de abril de 2002, que dispõe sobre a Lingua Brasileira de Sinais - Libras, e o art. 18 da Lei $N^{0}$ 10.098, de 19 de dezembro de 2000. Disponível em: http://www.planalto.gov.br/CCIVIL/_Ato2004-2006/2005/Decreto/D5626.htm. Acesso em: 12 dez. 2018.

BRASIL. Lei de Diretrizes e Bases da Educação Nacional. Lei número 9394, 20 de dezembro de 1996. Disponível em: http://www.planalto.gov.br/ccivil_03/leis/19394.htm. Acesso em: 20 maio 2019.

CAMPELlO, A. R. S.; REZENDE, P. L. F. Propostas para a elaboração de uma Política Nacional de Educação Bilingue para Surdos. Rio de Janeiro: FENEIS - Federação Nacional de Educação e Integração dos Surdos, 2012.

COSTA, O. S.; LACERDA, C. B. F. A Implementaçao da Disciplina de Libras no Contexto dos Cursos de Licenciatura. Revista Ibero-Americana de Estudos em Educação. Araraquara, v. 10, n. esp., p. 759-772, 2015.

FELIPE, T. A. Libras em Contexto: curso básico: livro do professor. 8. ed. Brasília: Ministério da Educação, Secretaria de Educação Especial, 2007.

FERREIRA BRITO, L. Por uma Gramática da Lingua de Sinais. Rio de Janeiro: Tempo Brasileiro, 1995.

FISCHER, R. M. B. A Paixão de Trabalhar com Foucault. In: M. V. Costa (Org.) Caminhos Investigativos I: Novos olhares nas pesquisas em educação. Rio de Janeiro: Ed. Lamparina, 2007. p. 39-60.

FOUCAULT, M. O Cuidado com a Verdade. In: FOUCAULT, M. (Org). Ditos e Escritos. Ética, Sexualidade, Política. Rio de Janeiro: Forense Universitária, 2006. p. 240-251. 
GESSER, A. Construindo e Legitimando a identidade intérprete e as atividades de interpretação: reflexões em aulas de Libras para ouvintes. Anuário da produção acadêmica docente (Anhanguera Educacional. Valinhos), v. 21, p. 127-146, 2012.

GESSER, A. LIBRAS? Que língua é essa?: crenças e preconceitos em torno da língua de sinais e da realidade surda. São Paulo: Parábola Editorial, 2009.

GIROTO, C. R. M.; MARTINS, S. E. S. de O.; LIMA, J. M. R. Formação de Professores e Inserção da Disciplina de Libras no Ensino Superior: perspectivas atuais. Revista IberoAmericana de Estudos em Educação, Araraquara, v. 10, n. esp., p.741-757, 2015.

HALL, S. A. Centralidade da Cultura: notas sobre as revoluções culturais do nosso tempo. Educação e Realidade, v. 22, n. 2, jul/dez., 15-46, 1997.

IACHINSKI, L.T. et al. A Inclusão da Disciplina de Libras nos Cursos de Licenciatura: visão do futuro docente. Audiology Communication Research, São Paulo - SP, v. 24, p. 1-7, 2019.

LACERDA, C. B. F.; CAPORALI, S. A; LODI, A. C. Questões preliminares sobre o ensino de língua de sinais a ouvintes: reflexões sobre a prática. Distúrbios da Comunicação, São Paulo, v. 16, n. 1, p. 53-63, 2004.

LEMOS, A. M.; CHAVES, E. P. A disciplina de Libras no ensino superior: da proposição à prática de ensino como segunda língua. In: ENDIPE - Encontro Nacional de Didática e Práticas de Ensino, XVI ENDIPE, 2012, UNICAMP - Campinas, Anais do XVI ENDIPE. p. 2282-2293.

MARTINS, V. R. O. Análise das vantagens e desvantagens da Libras como disciplina curricular no ensino superior. Cadernos do CEOM, Chapecó, v. 21, n. 28, p. 191-206, 2008.

MARTINS, V. R. O.; RIBEIRO, L. C. R. Algumas Análises da Disciplina de Libras nos Cursos de Licenciatura: reflexões e desdobramentos. Revista Intellectus. Jaguariúna, v. 3, n. 30, p. 15-37, 2015.

MÉLO, S. C. B. A Inserção da Disciplina de Libras no Curso de pedagogia: reflexões e desafios. Afluente: Revista de Letras e Linguística, v. 4, n.11, p. 47-59, 2019.

MERCADO, E. A. O significado e implicações da inserção de libras na matriz curricular do curso de pedagogia. In: ALBRES, N. A. Libras em estudo: ensino-aprendizagem. São Paulo: FENEIS- SP, 2012. p. 57-78.

NASCIMENTO, G. V. S.; SILVA, S. C. A. M.; NANTES, J. M. A disciplina Libras no currículo do Ensino Superior: Desafios e perspectivas para a formação de professores. In: $V$ Congresso Brasileiro de Educaşão Especial e VII Congresso Nacional dos Pesquisadores da Educação Especial, n. V e VII, 2012, São Carlos: UFSCar. Anais... 2012. p. 12222-12237.

NASCIMENTO, L.C.R; SOFIATO, C.G. A Disciplina de Língua Brasileira de Sinais no Ensino Superior e a Formação de Futuros Educadores. ETD - Educaşão Temática Digital, Campinas, v.18, n. 2, p. 352-368, abr./jun. 2016.

PEREIRA, T. L. Os desafios da implementação do ensino de Libras no Ensino Superior. 2008. 94 folhas. Dissertação (Mestrado em Educação) - Programa de Pós-graduação em Educação, Centro Universitário Moura Lacerda de Ribeirão Preto, 2008. 
PINHEIRO, D. You Tube como Pedagogia Cultural: espaço de produção, circulação e consumo da cultura surda. 2012. 80f. Dissertação (Mestrado em Educação) Universidade Federal de Santa Maria, UFSM, Santa Maria, 2012.

SANTOS, A. N.; KLEIN, M. Disciplina de Libras: o que as pesquisas acadêmicas dizem sobre a sua inserção no ensino superior? Revista Reflexão e Ação, Santa Cruz do Sul, v. 23, n. 3, p. 9-29, set./dez. 2015.

VITALINO, C. R.; DALL'ACQUA, M. J. C.; BROCHADO, S. M. D. A disciplina de Língua Brasileira de Sinais nos currículos dos cursos de Pedagogia. Boletim técnico do Senac: a revista da educação profissional. Rio de Janeiro: Senac/Departamento Nacional/Gerência de Marketing e Comunicação, v. 39, n. 2, p. 106-121, maio/ago., 2013.

WEIZ, T. O Diálogo entre o Ensino e a Aprendizagem. São Paulo: Ática, 2000.

RECEBIDO: $28 / 11 / 2019$

APROVADO: 28/05/2020

RECEIVED: $11 / 28 / 2019$

APPROVED: 05/28/2020

RECIBIDO: 28/11/2019

APROBADO: 28/05/2020 